Article

\title{
The Frequency of Focal Thyroid Incidental Findings and Risk of Malignancy Detected by 18F-Fluorodeoxyglucose Positron Emission Tomography in an Iodine Deficient Population
}

\author{
Nina Gedberg ${ }^{1}$, Jesper Karmisholt ${ }^{2,3}$, Michael Gade ${ }^{4}$, Rune V. Fisker ${ }^{4,5}$, Victor Iyer ${ }^{4}$ \\ and Lars J. Petersen $3,4, *$ (D) \\ 1 Department of Otolaryngology, Aarhus University Hospital, DK-8000 Aarhus, Denmark; \\ ninagedbjerg@gmail.com \\ 2 Department of Endocrinology, Aalborg University Hospital, DK-9000 Aalborg, Denmark; jsk@rn.dk \\ 3 Department of Clinical Medicine, Aalborg University, DK-9000 Aalborg, Denmark \\ 4 Department of Nuclear Medicine, Clinical Cancer Research Centre, Aalborg University Hospital, \\ DK-9000 Aalborg, Denmark; michael.g@rn.dk (M.G.); rvf@rn.dk (R.V.F.); petctiyer@gmail.com (V.I.) \\ 5 Department of Radiology, Aalborg University Hospital, DK-9000 Aalborg, Denmark \\ * Correspondence: lajp@rn.dk; Tel.: +45-9766-5480
}

Received: 25 June 2018; Accepted: 17 July 2018; Published: 17 July 2018

\begin{abstract}
Incidental focal uptake of 18F-fluorodeoxyglucose (FDG) in the thyroid on positron emission tomography (PET/CT) is rare but often associated with malignancy. The epidemiology of thyroid incidentalomas has only to some extent been described in countries with iodine deficiency. Here we report data from Denmark, a country with known iodine deficiency and wide access to PET/CT. All FDG PET/CT comprising the head and neck region, during 2014, were retrospectively reviewed, and patients with focal FDG uptake in the thyroid gland were identified. A total of 2451 patients had an FDG PET/CT of which 59 (2.4\%) patients presented with FDG-avid focal lesions in the thyroid gland. Among the 59 patients with FDG-avid lesions, 33 patients (56\%) received work up with ultrasound, thyroid technetium scintigraphy, fine needle aspiration, and/or histology of which 20 patients had a conclusive pathology report. Ten patients with FDG-avid lesions were identified with thyroid malignancy. The risk of thyroid malignancy was $16.9 \%$ among patient with incidental FDG-avid thyroid lesions. Our findings indicated a similar frequency of FDG thyroid incidentalomas and malignancy rates in an iodine deficient population compared to summary data from prior studies, studies mostly performed in geographical areas of normal or excess iodine supplementation.
\end{abstract}

Keywords: Denmark; incidental findings; iodine deficiency; neoplasms; positron emission tomography; thyroid

\section{Introduction}

Incidental imaging findings in a tissue or organ in patients without signs or symptoms of disease in that tissue (incidentalomas) are frequently occurring [1]. Incidental findings with 18 F-fluorodeoxyglucose positron emission tomography/computer tomography (FDG PET/CT) has been reported in several tissues [2], including colon [3], prostate [4], breast [5], and the adrenal glands [6].

Thyroid incidentalomas are common in imaging, but the risk of an underlying malignancy varies greatly depending on the imaging modality used [7] and the proportion of thyroid nodules in the background population [8]. A notable number of studies and systematic reviews have investigated the frequency and malignancy rate of FDG-avid thyroid incidentalomas in PET/CT [9-12]. A total 
of 32 original retrospective reports showed a median frequency of $2.3 \%$ of FDG-avid lesions in the populations studied, with thyroid cancer in nearly one in every three patients with focal FDG-avid thyroid lesions with follow up [12].

Most of the current retrospective studies on FDG incidentalomas have been performed in countries with normal or excess iodine supply, e.g., USA and South Korea [12-14]. Iodine deficiency is present in several parts of the World, including many areas of Europe (e.g., Scandinavia), Middle East, and Africa [14-16]. Low iodine supply may cause a high proportion of thyroid nodules in the population [8]. Only a few papers on FDG-avid thyroid incidentalomas have been published from iodine-deficient areas of Europe, namely two papers from Italy [17,18], one from UK [19] and one from Sweden [20]. These papers have consistently reported frequencies of $1.0-1.8 \%$ for FDG-avid focal lesions, well below the median frequency of $2.3 \%$ among the 32 currently published papers [12]. In contrast, the reported malignancy rates among patients with focal thyroid FDG uptake and subsequent follow-up in these four papers ranged from $23 \%$ in the UK, $34-43 \%$ in Italy, to $59 \%$ in Sweden compared to a median proportion of $32 \%$ among 32 papers [12].

Several issues warrant additional studies on the epidemiology and malignancy rates of FDG-avid incidentalomas. First, more studies are required from areas with low iodine supplementation due to conflicting data of the scarce published reports. In Denmark, up to $39 \%$ of women in the age 60-65 years have one or more thyroid nodules over $10 \mathrm{~mm}$ on ultrasound [21], but thyroid cancer is relatively infrequent [22]. Second, the access to PET/CT, and thereby the patient population referred for FDG PET/CT, varies greatly, even among European countries [23]. The number of PET/CT scanners and PET/CT examinations per inhabitants in Denmark are among the highest in the World [24]. The purpose of this work was to investigate the frequency and malignancy rates of focal, FDG-avid thyroid lesions in an iodine-deficient population with wide access to FDG PET/CT.

\section{Materials and Methods}

\subsection{Patients}

We retrospectively reviewed all FDG PET/CT that included the head and neck region and were performed at our institution from 1 January to 31 December 2014. Our department performed PET/CT for all patients in the Region North, Denmark; an area covering approximately 600,000 inhabitants. Patients were included in this study if the PET report identified focal FDG-uptake confined to the thyroid gland, excluding patients with diffuse thyroid FDG uptake. Patients with known malignant thyroid disease at the time of the PET/CT, as well as patients with a recent fine needle aspiration of the thyroid were excluded, so were patients with focal FDG uptake in the thyroid shown in any prior PET/CT. From the electronic medical record system, we registered data from thyroid ultrasound, thyroid scintigraphy, clinical follow-up, and the description of the pathological sample from the thyroid (fine needle aspiration of the lesion, pathological examinations of surgical specimens). The data registration was performed for at least 24 months after the PET/CT and was terminated in October 2017. Any patients with thyroid malignancy proven by pathology within 24 months from the PET/CT were registered as thyroid malignancy in our study. The Bethesda reporting system for cytopathology was used [25].

\subsection{Imaging Details}

The PET/CT was performed on a Discovery VCT scanner (GE Healthcare, Waukesha, WI, USA) in accordance with institutional procedures. The mean activity of FDG activity was $370 \mathrm{MBq}$. Blood glucose levels were less than $11 \mathrm{mmol} / \mathrm{L}$ in all patients. The PET/CT was acquired approximately $60 \mathrm{~min}$ after tracer injection. The $\mathrm{CT}$ scan was performed as low-dose $\mathrm{CT}$ or diagnostic $\mathrm{CT}$ with contrast-enhancement.

Classification of pathological FDG uptake in the thyroid was based on clinical impression (relative uptake in the thyroid versus background and/or asymmetry) and supported by semi-quantitative analysis of the uptake by calculation of standardized uptake value (SUV). Per institutional practice, 
all FDG PET/CT scans were read independently by two trained hybrid imaging specialists, in most cases a nuclear medicine physician and a radiologist, and a final diagnosis of pathological FDG uptake was made in consensus. For this study, the CT scans were used exclusively to verify the thyroidal confinement of the FDG-avid lesions.

\subsection{Approvals}

This quality assurance study was approved by the Danish Data Protection Agency at Region Nordjylland and covered by the general approval obtained by the region (2008-58-0028). The approval carried a waiver for informed consent to medical files. Retrospective studies do not require approval by Ethical Committees according to national legislation.

\subsection{Statistics}

All statistical tests were performed using SPSS ver. 24.0 (SPSS IBM, Armonk, NY, USA). Summary data are expressed as number and percentage, mean \pm standard deviation (SD) or median (range), depending on the distribution of data.

\section{Results}

A total of 2451 patients had a PET/CT covering the head and neck region of which 59 (2.4\%) patients presented with an incidental, focal FDG-avid lesion in the thyroid (Table 1). The mean age of patients with FDG-avid lesions was 69 years, nearly $70 \%$ of patients were women, many patients had a known non-thyroidal cancer at the time of referral, and patients were referred from a variety of medical specialities. The reason for PET/CT was cancer in most patients (95\%), equally distributed among patients with known cancer and patients suspected of cancer or recurrent cancer.

Table 1. Patient demographics, follow up, and final pathological diagnosis among the 59 patients with FDG-avid focal thyroid uptake.

\begin{tabular}{|c|c|}
\hline Variable & Data \\
\hline Number of patients & 59 \\
\hline Age $($ mean \pm SD) & $68 \pm 9$ years \\
\hline Sex distribution & 40 females $(68 \%), 19$ males $(32 \%)$ \\
\hline $\begin{array}{c}\text { Known, non-thyroidal cancer at referral } \\
\text { Cause of FDG PET/CT }\end{array}$ & $35(59 \%)$ \\
\hline Known cancer (pathology-verified) & $29(49 \%)$ \\
\hline Staging & 16 \\
\hline Therapy monitoring & 6 \\
\hline Cancer of unknown primary & 7 \\
\hline Suspected cancer & $27(46 \%)$ \\
\hline Suspected recurrence & 6 \\
\hline Suspected cancer & 21 \\
\hline Non-cancer (infection) & $3(5 \%)$ \\
\hline \multicolumn{2}{|l|}{ Referring medical specialties } \\
\hline Pulmonary medicine & $20(34 \%)$ \\
\hline Surgical gastroenterology & $13(22 \%$ \\
\hline Oncology/Hematology & $9(15 \%)$ \\
\hline Gynecology & $5(8 \%)$ \\
\hline Otolaryngology & $4(7 \%)$ \\
\hline Other & $8(14 \%)$ \\
\hline Imaging or pathology follow-up & $33(56 \%)$ \\
\hline Thyroid ultrasound & 31 \\
\hline Fine needle aspiration & 17 \\
\hline Thyroid scintigraphy & 15 \\
\hline Surgery & 13 \\
\hline Autopsy & 1 \\
\hline
\end{tabular}

Abbreviations: FDG PET/CT: 18F-fluorodeoxyglucose positron emission tomography/computer tomography; SD: Standard deviation. 
Approximately $50 \%$ of the patients $(n=33)$ had imaging and/or pathology follow-up, mostly with ultrasound. Twenty-one patients had cytology, pathology or both of which $20(34 \%)$ patients had a definitive cytological or histological diagnosis. One patient was diagnosed with a benign colloid nodule at autopsy. During a follow up period of two years, ten patients were diagnosed with thyroid cancer (nine cases of papillary carcinoma and one case of medullary carcinoma). Ten patients had benign pathology (eight cases of colloid nodules and two cases of thyroiditis). There were no cases of late thyroid malignancy ( $>2$ years after the PET/CT) in any patients.

The proportion of pathology-proven thyroid malignancy was $16.9 \%$ among patients with FDG-avid thyroid lesions, 30.3\% among patients with FDG-avid lesions who received follow-up, and $50.0 \%$ among patients with pathology as reference test (Table 2). Summary data from a recent systematic review is tabulated in Table 2 for comparison [12].

Table 2. Main findings of this study compared to summary data from 32 retrospective papers presented in a recent systematic review by Asmar et al. [12].

\begin{tabular}{lcc}
\hline \multicolumn{1}{c}{ Populations } & This Study & $\begin{array}{c}\text { Asmar et al., 2017 } \\
\text { (Median and Range) * }\end{array}$ \\
\hline $\begin{array}{l}\text { Study population, } n \\
\text { Patients with incidental, focal FDG-avid thyroid lesions, } n\end{array}$ & 2451 & $4330(32-49,519)$ \\
Proportion of patients with FDG-avid thyroid lesions & $2.4 \%$ & $80(19-1.151)$ \\
Patient with follow up, $n$ & 33 & $2.3 \%(0.1-10.1)$ \\
Proportion of patients with follow up & $56 \%$ & $38(11-211)$ \\
Patients with a conclusive pathology report, $n$ & 20 & $48 \%(11-100)$ \\
Patients with proven thyroid malignancy, $n$ & 10 & $12(3-72)$ \\
\hline Thyroid malignancy data & & \\
\hline$\quad \begin{array}{l}\text { Malignancy among patients with FDG-avid lesions } \\
\text { Malignancy among patient with FDG-avid lesions }\end{array}$ & $16.9 \%$ & $31.5 \%(12.4-63.6)$ \\
$\quad \begin{array}{l}\text { and follow-up } \\
\text { Malignancy among patients with FDG-avid lesions }\end{array}$ & $30.3 \%$ & Not reported \\
\hline
\end{tabular}

Abbreviation: FDG: 18F-fluorodeoxyglucose. * Data are captured from individual reports listed in Asmar et al., 2017 and summarized.

Among those 26 patients without follow-up, 21 (84\%) patients had a diagnosis of cancer at the time of the PET/CT or was diagnosed with cancer during the follow-up period. Thirteen patients died from non-thyroid cancer within one year of the PET/CT. None of the 26 patients were diagnosed with thyroid malignancy at the end of the observation period. There was no follow-up for thyroid malignancy among the 2000 or more patients without FDG-avid thyroid lesions. Illustrative examples of focal FDG uptake are shown in Figure 1.

Thirty-five patients had a non-thyroid cancer at the time of the PET/CT (Table 1, 29 patients with known cancer referred for PET and 6 patients with suspected recurrence), 13 patients were diagnosed with malignancy after the PET/CT, including 10 patients with thyroid malignancy, whereas $11(18.6 \%)$ patients were not diagnosed with any cancer within the observation period after PET/CT. 


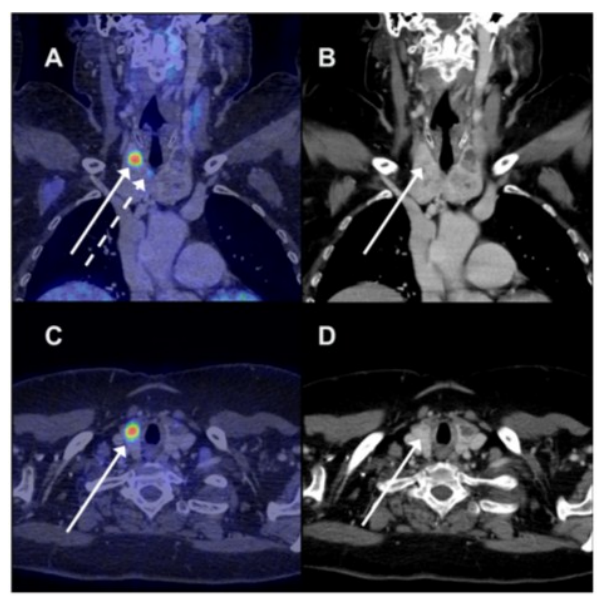

(a)

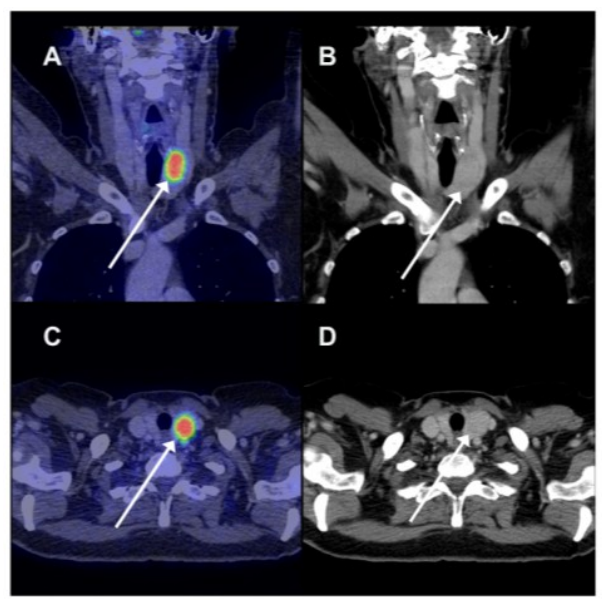

(b)

Figure 1. (a) A 69-year woman had a 18F-fluorodeoxyglucose positron emission tomography/computer tomography (FDG PET/CT) scan because of suspected pancreatic cancer (not verified). There was incidental FDG uptake in three lesions in the right thyroid. The patient underwent total thyroidectomy; pathology showed papillary adenocarcinoma in all three PET-avid lesions. (A) Fused coronal PET/CT images showed intense FDG uptake (standardized uptake value, SUV 9.8) in the upper right part of the right thyroid (full white arrow). Another site of pathological FDG uptake was seen on this coronal slice as well (dotted white arrow). (B) The CT image showing a bilateral nodular goiter with an arrow indicating the site of most intense FDG uptake on the fused images. $(C+D)$ Corresponding transverse images of the fused PET/CT images and CT scan with the most intense FDG-avid lesion; (b) An FDG $\mathrm{PET} / \mathrm{CT}$ was performed in a 69-year woman due to suspicion of ovarian cancer (confirmed). Incidental FDG uptake was seen in the left lobe. A fine needle aspirate showed benign findings (colloid nodule). Any false-negative findings were ruled out during clinical and imaging follow. (A) Fused coronal PET/CT images showed intense FDG uptake (SUV 11.0) in the upper right part of the right thyroid (full white arrow). (B) The CT image showing a bilateral nodular goiter with an arrow indicating the most intense site of pathological FDG uptake on the fused images. $(C+D)$. Corresponding transverse images of the fused PET/CT images and CT scan of the most intense FDG-avid lesion.

\section{Discussion}

Incidental focal increased uptake of FDG in the thyroid on PET/CT has been described in a number of studies. However, there is a very limited number of publications from countries with documented iodine-deficiency, and these reports have shown conflicting results. To what extent wide access to PET/CT had any influence on the epidemiology of FDG PET/CT incidentalomas are not previously reported. We assessed the epidemiology of FDG-avid thyroid lesions in Denmark, a population deficient of iodine and an unparalleled access to FDG PET/CT for oncology and non-oncology indications. We concluded that the proportion of FDG-avid thyroid nodules and the malignancy rates among the patients in this study were quite similar to data from studies performed in the other regions of the World.

The key findings in this report were demonstration of FDG-avid lesions in $2.4 \%$ of the total population and the malignancy rates, which were $17 \%$ in patients with FDG-avid lesions, 30\% among patients with focal FDG-avid lesions and follow-up, and 50\% in patients who had a conclusive cytology/pathology examination. These figures are very similar to data presented in recent systematic reviews on thyroid incidental findings by FDG PET/CT [10-12]. Prior reports seldom present data among patients with a final pathology examination. These data are available in this report. Absence of a final cytological and/or pathological reference, as seen in approximately one-third of the patients, was likely caused by ultrasound and/or thyroid scintigraphy findings without suspected nodules. 
It is remarkable that only approximately fifty percent of the patients with FDG-avid lesions received follow-up by ultrasound, thyroid scintigraphy and pathology examination by fine needle aspiration and/or surgical specimen examination. These findings likely reflect that the majority of the patients had, or subsequently were diagnosed with, non-thyroid malignancy at an advanced stage and died within the observation period. Our data confirmed a $50 \%$ cancer mortality rate within one year from the PET/CT in patients without work-up, and a cancer diagnosis in nearly $85 \%$ in these patients. The follow-up data are in line with data from previously published reports as shown in Table 2 [12].

It remains unclear if data on the epidemiology and malignancy rates of FDG-avid thyroid lesions are different in geographical areas with iodine-deficiency compared to no deficiency. Most published studies come from areas with normal or excess iodine supply. We found that $2.4 \%$ of the patients presented with FDG-avid focal lesions, which is similar to data from all regions published in systematic reviews, as shown in Table 2. However, the frequency of FDA-avid lesions in this report was higher than previously reported (1.0-1.8\%) from other iodine-deficient European countries like Italy [17,18], UK [19], and Sweden [20]. The malignancy rates among patients with FDG-avid lesions undergoing follow-up was $30 \%$ in this study compared to $34-42 \%$ in Italy, $23 \%$ in the UK, and $59 \%$ in Sweden. The reasons for this large variation remain speculative, but the composition of the patient population may be important. Denmark has a very high number of PET/CT scanners, adjusted for population size, and wide access to PET/CT via free public hospital care without insurance or reimbursement issues [24]. Less than $60 \%$ of the patients in this study had pathology-verified cancer at the time of the PET/CT, and approximately one in every five patients were not diagnosed with cancer within a follow-up period of 3 years from the PET. The other studies from iodine-deficient countries included FDG-avid patients with cancer only $[18,20]$ or included patients with known, as well as suspected cancer and/or infection without providing specific data by indication for a patient with focal FDG uptake $[17,19]$. Finally, the duration of the follow-up period was infrequently described in prior papers. Even though most thyroid cancers were detected in close relation to the initial work-up, we identified one patient with thyroid cancer, which was missed during the initial work-up but diagnosed within two years from the PET/CT.

The prevalence of thyroid nodules may notable influence the prevalence of thyroid incidentalomas, including FDG-avid lesions. Variation on thyroid nodule prevalences may interfere with epidemiological data on the frequency and malignancy rates of FDG-avid lesions. Nation-wide iodine fortification programs have generally been in place for many years in many iodine-deficient areas, including Denmark where it was initiated in $1997[8,26]$. However, recent follow-up data showed an inconsistent effect in such programs on iodine excretion, as well as thyroid volume changes $[27,28]$. Therefore, we as imaging specialists may expect to observe thyroid incidentalomas regularly in the years to come.

This study reported the frequency of thyroid incidental findings on FDG PET/CT performed as part of normal clinical practice. Two specialists always read the FDG PET/CT, and the conclusion was a consensus decision. We always had a radiologist trained in FDG PET to assist in the reading; in this context, the anatomical reading was of minimal importance, since the CT was mainly used to assure anatomical localization of incidental findings to the thyroid. The study did not examine observer variation in the identification of FDG-avid thyroid lesions; the study presented clinical findings as these were accessible to the referring physician.

Attempts have been made to identify the risk of thyroid malignancy among patients with FDG-avid lesions, e.g., lesion size and SUV. Such investigations have shown notable variation in SUV values among groups with malignant and benign thyroid lesions [18-20]. So far, the predictive values of individual variables remain uncertain. We did no calculations of SUV and/or sizes of the thyroid lesions. In addition, we did not measure the size of the thyroid incidentalomas, so any recommendations based on lesion size would be speculative. 


\section{Conclusions}

In conclusion, we found a low frequency of incidental thyroid lesions with focal increased uptake of FDG on PET/CT. However, the malignancy rate was high in patients with follow-up (30\%), reaching $50 \%$ in patients with pathology of the thyroid. Several guidelines recommend work-up of FDG-avid incidental findings by ultrasound $[29,30]$. The high rate of thyroid malignancy in patients with focal FDG-avid lesions suggest that a work-up of such lesions should include at least a fine needle aspiration cytology.

Author Contributions: N.G., R.V.F. and V.I. conceived and designed the study; N.G., M.G., and L.J.P. collected the data; N.G., J.K. and L.J.P. analyzed the data; N.G., J.K. and L.J.P. drafted the paper; all authors critically reviewed and manuscript and approved the final version.

Conflicts of Interest: The authors declare no conflict of interest. Outside this manuscript (and irrespective if related to the subject matter of this paper), Professor Petersen has received grant support from the Obel Foundation, has received fees for speaking at meetings arranged by Sanofi-Genzyme, Janssen Pharma, and Bayer; has been a paid participant in conferences by Sanofi-Genzyme and Bayer; and receives consulting fees from KLIFO Drug Development Council and ljpmedical. Karmisholt has received fees for speaking at meetings arranged by Sanofi-Aventis. The other authors declare no conflict of interest.

\section{References}

1. Lumbreras, B.; Donat, L.; Hernandez-Aguado, I. Incidental findings in imaging diagnostic tests: A systematic review. Br. J. Radiol 2010, 83, 276-289. [CrossRef] [PubMed]

2. Tamburello, A.; Treglia, G.; Albano, D.; Bertagna, F.; Giovanella, L. Prevalence and clinical significance of focal incidental 18F-FDG uptake in different organs: An evidence-based summary. Clin. Transl. Imaging 2017, 5, 525-532. [CrossRef]

3. Kousgaard, S.J.; Thorlacius-Ussing, O. Incidental colorectal FDG uptake on PET/CT scan and lesions observed during subsequent colonoscopy: A systematic review. Tech. Coloproctol. 2017, 21, 521-529. [CrossRef] [PubMed]

4. Bertagna, F.; Sadeghi, R.; Giovanella, L.; Treglia, G. Incidental uptake of 18F-fluorodeoxyglucose in the prostate gland. Systematic review and meta-analysis on prevalence and risk of malignancy. Nuklearmedizin 2014, 53, 249-258. [CrossRef] [PubMed]

5. Bertagna, F.; Treglia, G.; Orlando, E.; Dognini, L.; Giovanella, L.; Sadeghi, R.; Giubbini, R. Prevalence and clinical significance of incidental F18-FDG breast uptake: A systematic review and meta-analysis. Jpn. J. Radiol. 2014, 32, 59-68. [CrossRef] [PubMed]

6. Wong, K.K.; Arabi, M.; Bou-Assaly, W.; Marzola, M.C.; Rubello, D.; Gross, M.D. Evaluation of incidentally discovered adrenal masses with pet and PET/CT. Eur. J. Radiol. 2012, 81, 441-450. [CrossRef] [PubMed]

7. Uppal, A.; White, M.G.; Nagar, S.; Aschebrook-Kilfoy, B.; Chang, P.J.; Angelos, P.; Kaplan, E.L.; Grogan, R.H. Benign and malignant thyroid incidentalomas are rare in routine clinical practice: A review of 97,908 imaging studies. Cancer Epidemiol. Biomark. Prev. 2015, 24, 1327-1331. [CrossRef] [PubMed]

8. Carle, A.; Krejbjerg, A.; Laurberg, P. Epidemiology of nodular goitre. Influence of iodine intake. Best Pract. Res. Clin. Endocrinol. Metab. 2014, 28, 465-479. [CrossRef] [PubMed]

9. Bertagna, F.; Treglia, G.; Piccardo, A.; Giubbini, R. Diagnostic and clinical significance of F-18-FDG-PET/CT thyroid incidentalomas. J. Clin. Endocrinol. Metab. 2012, 97, 3866-3875. [CrossRef] [PubMed]

10. Soelberg, K.K.; Bonnema, S.J.; Brix, T.H.; Hegedus, L. Risk of malignancy in thyroid incidentalomas detected by 18F-fluorodeoxyglucose positron emission tomography: A systematic review. Thyroid 2012, 22, 918-925. [CrossRef] [PubMed]

11. Nayan, S.; Ramakrishna, J.; Gupta, M.K. The proportion of malignancy in incidental thyroid lesions on 18-FDG PET study: A systematic review and meta-analysis. Otolaryngol. Head Neck Surg. 2014, 151, 190-200. [CrossRef] [PubMed]

12. Asmar, A.; Simonsen, L.; Bulow, J.; Asmar, M. Work-up of thyroid incidentalomas identified by 18F-fluorodeoxyglucose PET/CT. Ugeskr. Laeger 2017, 179. 
13. Kang, M.J.; Hwang, I.T.; Chung, H.R. Excessive iodine intake and subclinical hypothyroidism in children and adolescents aged 6-19 years: Results of the sixth korean national health and nutrition examination survey, 2013-2015. Thyroid 2018, 28, 773-779. [CrossRef] [PubMed]

14. World Health Organization. Iodine Status Worldwide. Country Data on Median Urinary Iodine Concentrations and Urinary Iodine Concentrations in School Age Children <100 $\mu \mathrm{g} / \mathrm{L}$ 1993-2006. Available online: http:/ /www.who.int/vmnis/iodine/status/summary/IDD_estimates_table_2007.pdf? ua $=1$ (accessed on 28 May 2018).

15. De Benoist, B.; McLean, E.; Andersson, M.; Rogers, L. Iodine deficiency in 2007: Global progress since 2003. Food Nutr. Bull. 2008, 29, 195-202. [CrossRef] [PubMed]

16. Manousou, S.; Dahl, L.; Heinsbaek Thuesen, B.; Hulthen, L.; Nystrom Filipsson, H. Iodine deficiency and nutrition in scandinavia. Min. Med. 2017, 108, 147-158.

17. Pagano, L.; Sama, M.T.; Morani, F.; Prodam, F.; Rudoni, M.; Boldorini, R.; Valente, G.; Marzullo, P.; Baldelli, R.; Appetecchia, M.; et al. Thyroid incidentaloma identified by (1)(8)F-fluorodeoxyglucose positron emission tomography with CT (FDG-PET/CT): Clinical and pathological relevance. Clin. Endocrinol. 2011, 75, 528-534. [CrossRef] [PubMed]

18. Bertagna, F.; Treglia, G.; Piccardo, A.; Giovannini, E.; Bosio, G.; Biasiotto, G.; Bahij, E.K.; Maroldi, R.; Giubbini, R. F18-FDG-PET/CT thyroid incidentalomas: A wide retrospective analysis in three Italian centres on the significance of focal uptake and suv value. Endocrine 2013, 43, 678-685. [CrossRef] [PubMed]

19. Brindle, R.; Mullan, D.; Yap, B.K.; Gandhi, A. Thyroid incidentalomas discovered on positron emission tomography CT scanning-Malignancy rate and significance of standardised uptake values. Eur. J. Surg. Oncol. 2014, 40, 1528-1532. [CrossRef] [PubMed]

20. Nilsson, I.L.; Arnberg, F.; Zedenius, J.; Sundin, A. Thyroid incidentaloma detected by fluorodeoxyglucose positron emission tomography/computed tomography: Practical management algorithm. World J. Surg. 2011, 35, 269-2697. [CrossRef] [PubMed]

21. Knudsen, N.; Bulow, I.; Jorgensen, T.; Laurberg, P.; Ovesen, L.; Perrild, H. Goitre prevalence and thyroid abnormalities at ultrasonography: A comparative epidemiological study in two regions with slightly different iodine status. Clin. Endocrinol. 2000, 53, 479-485. [CrossRef]

22. Londero, S.C.; Krogdahl, A.; Bastholt, L.; Overgaard, J.; Pedersen, H.B.; Frisch, T.; Bentzen, J.; Pedersen, P.U.; Christiansen, P.; Godballe, C. Papillary thyroid carcinoma in denmark 1996-2008: An investigation of changes in incidence. Cancer Epidemiol. 2013, 37, e1-e6. [CrossRef] [PubMed]

23. Cuocolo, A.; Breatnach, E. Multimodality imaging in europe: A survey by the european association of nuclear medicine (EANM) and the european society of radiology (ESR). Eur. J. Nucl. Med. Mol. Imaging 2010, 37, 163-167. [CrossRef] [PubMed]

24. Hoilund-Carlsen, P.F.; Gerke, O.; Vilstrup, M.H.; Nielsen, A.L.; Thomassen, A.; Hess, S.; Hoilund-Carlsen, M.; Vach, W.; Petersen, H. PET/CT without capacity limitations: A danish experience from a european perspective. Eur. Radiol. 2011, 21, 1277-1285. [CrossRef] [PubMed]

25. Cibas, E.S.; Ali, S.Z. The bethesda system for reporting thyroid cytopathology. Am. J. Clin. Pathol. 2009, 132, 658-665. [CrossRef] [PubMed]

26. Laurberg, P.; Jorgensen, T.; Perrild, H.; Ovesen, L.; Knudsen, N.; Pedersen, I.B.; Rasmussen, L.B.; Carle, A.; Vejbjerg, P. The danish investigation on iodine intake and thyroid disease, danthyr: Status and perspectives. Eur. J. Endocrinol. 2006, 155, 219-228. [CrossRef] [PubMed]

27. Rasmussen, L.B.; Carle, A.; Jorgensen, T.; Knuthsen, P.; Krejbjerg, A.; Perrild, H.; Bjergved, L.; Sloth, J.J.; Laurberg, P.; Ovesen, L. Iodine excretion has decreased in denmark between 2004 and 2010-The importance of iodine content in milk. Br. J. Nutr. 2014, 112, 1993-2001. [CrossRef] [PubMed]

28. Krejbjerg, A.; Bjergved, L.; Pedersen, I.B.; Carle, A.; Jorgensen, T.; Perrild, H.; Ovesen, L.; Rasmussen, L.B.; Knudsen, N.; Laurberg, P. Iodine fortification may influence the age-related change in thyroid volume: A longitudinal population-based study (DanThyr). Eur. J. Endocrinol. 2014, 170, 507-517. [CrossRef] [PubMed] 
29. Horvath, E.; Silva, C.F.; Majlis, S.; Rodriguez, I.; Skoknic, V.; Castro, A.; Rojas, H.; Niedmann, J.P.; Madrid, A.; Capdeville, F.; et al. Prospective validation of the ultrasound based TIRADS (Thyroid Imaging Reporting And Data System) classification: Results in surgically resected thyroid nodules. Eur. Radiol. 2017, 27, 2619-2628. [CrossRef] [PubMed]

30. Russ, G.; Leboulleux, S.; Leenhardt, L.; Hegedus, L. Thyroid incidentalomas: Epidemiology, risk stratification with ultrasound and workup. Eur. Thyroid J. 2014, 3, 154-163. [CrossRef] [PubMed]

(C) 2018 by the authors. Licensee MDPI, Basel, Switzerland. This article is an open access article distributed under the terms and conditions of the Creative Commons Attribution (CC BY) license (http:/ / creativecommons.org/licenses/by/4.0/). 